Afterword

\title{
Afterword: Embodiment, Social Order, and the Classification of Humans as Waste
}

\author{
Chris Shilling \\ School of Social Policy, Sociology and Social Research, University of Kent, CNE114, \\ Cornwallis North East, Canterbury, Kent, CT2 7NF, UK; E-Mail: C.Shilling@kent.ac.uk; \\ Tel.: +44-01227-824014; Fax: +44-01227-827005
}

Received: 7 June 2013 / Accepted: 17 June 2013 / Published: 24 June 2013

The rise of body studies has, since its development in the early $1980 \mathrm{~s}$, been characterized by a resilience and creativity that shows no signs of abating. There are various reasons for this success, but two are especially worthy of note. Socially informed studies of the materialities, capacities and connectedness of body subjects have maintained their capacity to advance disciplinary, cross-disciplinary and inter-disciplinary work on the subject into new agendas [1,2]. Additionally, emerging studies in the field continue to facilitate a sustained interrogation of those residual categories that have helped to define, but also restrict, the reach and ambition of sociology and related disciplines, and advance our understanding of social actions, social relationships and societies. Thus, in contrast to the traditional sociological concern with abstract 'social facts' that threatened, at times, to render redundant a focus on the physical constitution of those subject to them [3], sociologists of embodiment have explored the corporeal consequences of social structures, while also highlighting how the bodily components of agency and interaction were affected by, and became meaningful to people through, such factors as health, illness and dis/ability.

Specific innovations in the field over the past few years-including the significance for body studies of the turn to affect, actor-network theory, and other elements of the 'new materialism' that focus on how the ontological complexities of bodies can be performed in various ways-have maintained this dynamism. Body studies are now engaging with such issues as the liveliness of inorganic as well as organic phenomena, the networked extensions to which bodies contribute and in which they are enmeshed, and the re-shaping of embodied subjects and dominant 'forms of embodiment' [4] through processes of intra-activity [5-7]. Here, there has been a particular concern with the pluralities and multiplicities of bodily existence, and the emergence of particular ways of living and being through practices that are simultaneously and inextricably material and social [8].

The contributions to this special issue of Societies have engaged with many of these concerns, in studies that range from Soldatic's analysis of the affectual milieu of disgust in which disabled women 
confront workfare programmes in Australia, to Marshall's and Katz's analysis of the 'agentic' potential of pharmaceuticals in re-naturalising conceptions of hetero-normativity among aging bodies. They are also sensitive to the power of body images to provide what Featherstone ([9], p. 198) has referred to as material 'prosthetic for imaginative work', exploring how embodied agency is shaped by and enmeshed within visceral invocations of becoming. Brayton's explorations of how media representations of physical labour are entangled with images and themes of muscular heterosexual masculinity and whiteness, for example, provide us with a palpable sense of the mimetic embodiment of value during an era wherein circuits of capital appear to have become increasingly 'disembodied'. Low's and Dupuis-Blanchard's analysis of media representations of aging bodies complements this focus by revealing the disciplinary logic informing apparently positive images of the performative capacities of seniors that place consumption and consumer culture at the heart of an anti-aging crusade.

In this brief afterword, however, I want to explicate the contribution made by these articles not only to these contemporary concerns, but also to one of the longest standing problems in sociology and the social sciences more generally, the Hobbesian 'problem of order' [10]. The puzzle of how humans can co-exist peacefully without social life degenerating into a war of all against all has been addressed in various ways [11], but sociology engaged historically with this issue via a Parsonian ([12], p. 768) concern with those institutionally embedded norms that have patterned the choices of individuals along societally acceptable directions. While this focus stimulated important developments, it tended to involve unexamined assumptions about who societies categorized as waste and who they disposed of in order to maintain governance [13]. As Munro [14] argues, this waste can be seen as residual to the discipline even though such classics as Anderson's [15], Whyte's [16] Street Corner Society, and Bittner's [17] The Police on Skid Row can be interpreted as analyses of the framing of particular groups of people as the 'detritus of social order' [18]. It remains residual, furthermore, despite being challenged by contemporary studies of health and the social services, which reveal how those who fail to conform to the normative expectations and embodied trajectories sanctioned by these organizations are treated as 'matter out of place' [19].

If the processes whereby humans are classified as waste remain marginal within much mainstream sociology, the writings of Agamben [20] and Douglas [19], in contrast, provide a focus on these issues that is of particular relevance to the articles in this collection. Interrogating the realm of bio-politics, that has become a major focus for research in recent years, Agamben [20] suggests that the politics of 'bare life' have come to dominate the modern world. In contrast to the emphasis on the virtuous life central to the Classical Polis, modern political regimes have expanded what was then the exceptional space in which outcasts were banished to the status of mere existence, outside the jurisdiction of political or divine law ([20], p. 140). In so doing, politics has been increasingly reduced to a situation in which the management of bodies is core to 'the mechanisms and calculations of State power'. The impact of this mode of control is evident across society; from debates about euthanasia, to attempts to monitor/control the weight of children, to the impact of neuroscience on policy ([20], pp. 3, 4, 111; $[21,22])$. Here, if embodied subjects fail to conform or perform to bodily norms, they stand to be classified as expendable waste; a waste that must be purified or hidden if society is to be maintained as a realm of order and productivity [19].

Against this background, what each of the contributions to this special issue reveals, in complementary but different ways, is the human cost associated with the management of bare life and 
associated bodily norms of purity and dirt in contemporary Western societies. Slater's analysis of the abstraction of youth into a commodity that needs to be invested in as a marker of respectability and normality, provides us with a context relevant to all of the papers in this special collection. Writing from a critical disability perspective, Slater explores how a particular ideal of youth-a symbol of beauty, health and fitness - is presented as a goal to which all adults and children should aspire; a goal that not only represents a flight from aging and morality, but also from frailty and disability.

If an idealized vision of youth represents some sort of normative order of biological existence in the current age, however, the sphere outside of its particular borders is indeed large. Depoy and Gilson address these wastelands directly by revealing the dehumanizing consequences people confront in contemporary societies when disability and illness advance to a stage that is resistant to pharmaceutical or technological rectification. Horejes and Heuer pursue the theme of technological mediation in this context, via a detailed investigation into deafness, exploring how doctors and audiologists possess their own typifications and classifications of the types of embodiment that deaf people should pursue and experience. In the case of children, as Horejes and Heuer point out, such typifications can have the force of law behind them.

In her analysis of how conceptions of normative orders have at their centre idealized visions of acceptable bodies, Malacrida undertakes, through a case study of the Michener Centre, Albert —a total institution for the accommodation of 'mental defectives' - a sustained exploration of the treatment of one category of those considered unassimilable to society. At its height in the late 1970s, this institution housed over 2,400 children and adults. Having removed these polluting 'undesirables' from the social body, Malacrida details how processes of abjection and 'othering' included the denial of personal and intimate space, the enforcement of deadening routines on inmates, the use of medication to ensure compliance, and the acceptance of routinized neglect and abuse. In so doing, she provides us with an indictment of how societies deal with those considered illegitimate in relation to the "modern obsession' with corporeal order and predictability and who, as a consequence, are treated as human waste.

If the politics of bare life incorporates within it presumptions about degrees of control, order, and paying respect to a youthful ideal, Soldatic focuses on the performative work that has to be done, in order to honour this norm, by disabled women who participate in Australian neoliberal workfare programmes. Here, she identifies the affectual framing of these women in terms of disgust. This disgust is constructed in relation to those able, 'respectable' embodied subjects who constitute the positive referent against which these disabled women fail, and its analysis by Soldatic provides us with insight into how bodies that dys-appear, intruding negatively upon the system of control in which they exist, can be positioned as a space of 'abnormality, freakery and depravity'.

While Malacrida and Soldatic focus respectively on processes of exclusion and coercion, Low's and Dupuis-Blanchard's analytical gaze rests upon more positive disciplinary exhortations to respect bio-political norms in their exploration of media representations of seniors. Suggesting that these are inflected with highly partial associations with physical fitness, race and class, the media they explore normalises a fight against ageing via consumption. Through highly idealized images and messages, there emerges a strong vision of the socially responsible aging citizen as someone who 'remains youthful as long as possible, contributes to the economy as a smart consumer and as an active 
participant in productive activities, and stays healthy to avoid accessing healthcare and other public services.'

The question of what is involved in maintaining membership of the corporeal citizenry for aging body-subjects is also explored by Marshall and Katz. Focusing on the biomedical reconfiguration of sexual functioning across the life course, they analyse how aging bodies exist within hetero-normative assumptions including a 'coital imperative' that 'enacts discursive closure on what properly sexed bodies are supposed to do' by fixing youthful standards of performance that can both liberate but also re-naturalise conventional ideas about gender and heterosexuality. Pharmaceuticals such as Viagra, and the creation of conditions such as Female Sexual Arousal Disorder, assist this reconstruction of corporeal normality through biosocial standards aimed at 'optimal functionality'.

These investigations of how bodies remain a ubiquitous medium for classifications of normality and abnormality, purity and waste, demonstrate the persistence and pervasiveness of some very traditional inequalities, but the contributors to this special volume also acknowledge that change can occur. Mallozzi's research maps the transformations to have taken place in culturally acceptable models of bodily images of women teachers in the United States in recent decades, for example, suggesting that conceptions of 'optimal images' of teachers are no longer as conservative as was once the case. Oro'-Piqueras's explorations of the dys-appearing body in literature provide another suggestion that the corporeal norms prevalent in society do not always reflect lived realities. Through a detailed exploration of Doris Lessings The Diary of a Good Neighbour and Margaret Forster's Have the Men Had Enough?, Oro'-Piqueras analyses the existence of agency in illness and dying and suggests that death might be seen as, and often is, an integral part of life.

In summary, the papers in this special edition of Societies provide us with complementary analyses that illustrate the implications of body matters to sociology and the social sciences. Connecting traditional disciplinary issues to new agendas - revolving in particular around the relationship between social orders and the creation of human waste - they constitute a valuable addition to the field of body studies.

\section{References and Notes}

1. Shilling, C. The Body and Social Theory; Sage: London, UK, 2012.

2. Routledge Handbook of Body Studies; Turner, B.S., Ed.; Routledge: London, UK, 2012.

3. Durkheim, E. The Rules of Sociological Method; Macmillan: Houndmills, UK, 1982.

4. Mellor, P.A.; Shilling, C. Re-forming the Body: Religion, Community and Modernity; Sage/TCS: London, UK, 1997.

5. Mol, A. The Body Multiple: Ontology in Medical Practice; Duke University Press: Durham, NC, USA, 2003.

6. Barad, K. Meeting the Universe Halfway; Duke University Press: Durham, NC, USA, 2007.

7. New Materialisms; Coole, D., Frost, S., Eds.; Duke University Press: Durham, NC, USA, 2010.

8. Michael, M.; Rosengarten, M. Medicine: Experimentation, politics, emergent bodies. Body Soc. 2012, 18, 1-17.

9. Featherstone, M. Body image and affect in consumer culture. Body Soc. 2010, 16, 193-221.

10. Levine, D. Visions of the Sociological Tradition; Chicago University Press: Chicago, IL, USA, 1995. 
11. Wrong, D. The Problem of Order. What Unites and Divides Society; Harvard University Press: Cambridge, MA, USA, 1994.

12. Parsons, T. The Structure of Social Action; The Free Press: New York, NY, USA, 1968; Volume 1.

13. Shilling, C. Series editor's introduction. In Waste Matters: New Perspectives on Food and Society; Evans, D., Campbell, H., Murcott, A., Eds.; The Sociological Review Monograph Series; Wiley: Hoboken, NJ, USA, 2013; pp. 1-4.

14. Munro, R. The disposal of place: Facing modernity in the Kitchen-diner. Sociol. Rev. 2013, 60, 212-231.

15. Anderson, N. The Hobo. The Sociology of the Homeless Man; Chicago University Press: Chicago, IL, USA, 1923.

16. Whyte, W.F. Street Corner Society. The Social Structure of an Italian Slum; Chicago University Press: Chicago, IL, USA, 1943.

17. Bittner, E. The police on skid row: A study of peace keeping. Am. Socio. Rev. 1967, 32, 699-717.

18. These studies thus constitute critically informed contributions to our understanding of the relationship between the construction of social order and the classification of humans as waste.

19. Douglas, M. Purity and Danger; Routledge: London, UK, 2002/1966.

20. Agamben, G. Homo Sacer. Sovereign Power and Bare Life; Stanford University Press: Palo Alto, CA, USA, 1998.

21. Wastell, D.; White, S. Blinded by neuroscience: Social Policy and the myth of the infant brain. Families Relat. Soc. 2012, 1, 397-414.

22. Wright, J.; Harwood, V. Biopolitics and the 'Obesity Epidemic'; Routledge: London, UK, 2012.

(C) 2013 by the authors; licensee MDPI, Basel, Switzerland. This article is an open access article distributed under the terms and conditions of the Creative Commons Attribution license (http://creativecommons.org/licenses/by/3.0/). 